CrossMark \&lick for updates

Cite this: Polym. Chem., 2015, 6, 55

\title{
Improve the photovoltaic performance of new quinoxaline-based conjugated polymers from the view of conjugated length and steric hindrance
}

\author{
Dan Ouyang, ${ }^{\text {a,b }}$ Manjun Xiao, ${ }^{c}$ Dangqiang Zhu, a,b Weiguo Zhu, ${ }^{c}$ Zhengkun Du, a,b \\ Ning Wang, ${ }^{* a}$ Yuanhang Zhou, ${ }^{a, b}$ Xichang Bao ${ }^{a}$ and Renqiang Yang ${ }^{* a}$
}

\begin{abstract}
In this work, we have synthesized two new quinoxaline derivatives: 2,3-bis(n-octylthiomethyl)-5,8-dibromoquinoxaline (QS) and 2,3-bis[(5-octylthio)thiophen-2-yl]-5,8-dibromoquinoxaline (QTS); in addition, three new donor-acceptor (D-A) copolymers: poly\{4,8-bis(2-ethylhexyloxy)-benzo[1,2-b:4,5-b']-dithiophenealt-2,3-bis(n-octylthiomethyl)quinoxaline\} (PBDTQS), poly\{4,8-bis(2-ethylhexyloxy)-benzo[1,2-b:4,5-b']dithiophene-alt-2,3-bis[(5-octylthio)thiophen-2-yl]quinoxaline\} (PBDTQTS), and poly\{2,3-bis[(5octylthio)thiophen-2-yl]quinoxaline-5,8-diyl-alt-thiophene-2,5-diyl\} (PTQTS) were designed from the view of extending the length of conjugated side chain and reducing the steric hindrance of building blocks. Replacing the carbon atom in the side chain of polymer PBDTQS with a thiophene ring could increase the conjugation length and improve the absorption in the visible region of the copolymer PBDTQTS and PTQTS. Furthermore, polymer PTQTS exhibited a more planar backbone and increased intermolecular $\pi$-stacking compared to PBDTQTS, which was because the thiophene unit in PTQTS had smaller size and less steric hindrance than those of benzo[1,2-b:4,5- $\left.b^{\prime}\right]$-dithiophene unit in PBDTQTS. For the optimized polymer solar cell of PTQTS : $\mathrm{PC}_{61} \mathrm{BM}, \mathrm{PCE}$ of $3.73 \%$ with $\mathrm{V}_{\text {oc }}$ of $0.76 \mathrm{~V}, \mathrm{~J}_{\mathrm{sc}}$ of $9.41 \mathrm{~mA} \mathrm{~cm}^{-2}$ and FF of $52.33 \%$ under an AM $1.5 \mathrm{G}$ solar simulator with an intensity of $100 \mathrm{~mW} \mathrm{~cm}{ }^{-2}$ was achieved, which was the best performance among the three copolymers. The results implied that the PTQTS with thiophene as the donor unit and QTS as the acceptor unit in the main chain would be a promising donor candidate in the application of polymer solar cells.
\end{abstract}

Received 2nd August 2014,
Accepted 29th August 2014

DOI: $10.1039 / c 4 p y 01061 b$

www.rsc.org/polymers developed and various chemical modifications have been used to optimize the physical and photovoltaic properties of the D-A polymers. ${ }^{12-16}$ PCE has exceeded $9 \%$ for single junction solar cells ${ }^{17,18}$ and $10 \%$ for tandem solar cells. ${ }^{19,20}$

It is still very challenging to simultaneously balance the absorptions, energy levels, and charge mobilities of PSCs for linear D-A conjugated polymers. In recent years, side chain conjugated polymers, which had the donor or acceptor building block with conjugated structure in the side chain directions, are attracting attention for modulating the electronic structures of polymers. ${ }^{21-25}$ Based on this strategy, Hou et al. have successfully proven the benzo[1,2-b:4,5- $\left.b^{\prime}\right]$-dithiophene (BDT)-polymers with conjugated structure in the side chain directions show higher hole transport property and photovoltaic performance. ${ }^{26}$ In addition, some acceptor building blocks, with conjugated side chain have also been reported. ${ }^{27}$ For example, a prospecting conjugated polymer poly[2,3-bis(3-(octyloxy)phenyl)quinoxaline-alt-thiophene] (TQ) exhibited excellent photovoltaic performance with a PCE of $6.0 \%$, opencircuit voltage $\left(V_{\mathrm{oc}}\right)$ of $0.89 \mathrm{~V}$, short-circuit current $\left(J_{\mathrm{sc}}\right)$ of $10.5 \mathrm{~mA} \mathrm{~cm}^{-2}$ and fill factor (FF) of $64 \%{ }^{28}$ The two substituted 
benzene groups on the quinoxaline rings could freely rotate, thus potentially hinder the intermolecular packing and further influence charge carrier mobility of the copolymers. Therefore, some groups designed new quinoxaline derivatives by replacing a phenyl group with a thiophene moiety, ${ }^{29,30}$ which may further improve the absorption capability of the donor materials.

Moreover, it is important to improve the packing orders of the D-A conjugated polymer because the mobility of the polymer film is highly related to the inter-chain $\pi-\pi$ stacking of the polymers. Considering the donor-acceptor interaction and the spatial steric hindrance caused by the branched alkyl chains, it could be better that the small donor units dock into the cavity of large acceptor cores. ${ }^{31}$ This "molecular docking" strategy would reduce the steric hindrance of side chains and increase the inter-chain $\pi-\pi$ stacking of the polymer, and improve the carrier mobility of the active layer in devices. Pei's group has introduced a "molecular docking" strategy and demonstrated that polymer symmetry and backbone curvature affect the inter-chain of isoindigo-based polymers in film, ultimately leading to improved device performance. ${ }^{32}$

Based on the above considerations, a delicate balance between the steric hindrance and conjugated length is needed via judiciously designed polymers. For example, it is well known that increasing the length of the side chains will enhance the steric hindrance, thus increase the solubility of the polymer, which may further lead to better film processability. ${ }^{33}$ However, it is also obvious that too much steric hindrance will force the backbone of the polymer to bend out of coplanarity, which may influence the mobility and light-harvesting ability of the active layer. ${ }^{34}$ In the case of conjugated length, a similar problem exists. Large conjugated length will enhance the $\pi-\pi$ stacking and decrease the band gap of the polymers, which would surely increase the mobility and light harvesting-ability of the active layer. ${ }^{35}$ However, if the conjugated length is significantly large, the solubility and film processability of the polymers will be influenced, which may further affect the morphology of the active layer. ${ }^{36}$ In this context, we tried to improve the photovoltaic performance of quinoxaline-based conjugated polymer from the view of both conjugated length in the side chain direction and steric hindrance of building blocks. Firstly, we introduced an alkylthio substitute on the quinoxaline and synthesized a new low band gap conjugated polymer poly\{4,8-bis(2-ethylhexyloxy)-benzo[1,2- $b: 4,5$ - $\left.b^{\prime}\right]$-dithiophene-alt-2,3-bis(n-octylthiomethyl)quinoxaline\} (PBDTQS). To our knowledge, a quinoxaline segment containing an alkylthio substitute group has not been reported. Sulfur atom has some $\pi$-acceptor capability due to the formation of $\mathrm{p}_{\pi}(\mathrm{C})-\mathrm{d}_{\pi}(\mathrm{S})$ orbital overlap, where divalent sulfur accepts $\pi$-electron from the p-orbital of carbon-carbon double bond into its empty $3{ }_{\mathrm{d}}$-orbitals. ${ }^{37,38}$ This causes the polymers containing alkylthio side chain to exhibit unique optoelectronic properties such as broader absorption spectra ${ }^{39}$ and lower the highest occupied molecular orbital (HOMO) energy level. ${ }^{40,41}$ In our strategy, the incorporation of alkylthio side chain into quinoxaline monomers may be a promising method to down-shift the HOMO energy level to certain extent. ${ }^{10}$ To increase the conjugated length in the side chain direction, we replaced a carbon atom with a thiophene unit and synthesized another copolymer, namely, poly\{4,8-bis(2-ethylhexyloxy)-benzo[1,2- $b: 4,5$ - $\left.b^{\prime}\right]$-dithiophene-alt-2,3-bis[(5-octylthio)thiophen-2-yl]quinoxaline $\}$ (PBDTQTS). In our design strategy, the advantage of the alkylthio side chain and the thiophene ring in the quinoxaline are expected to be combined, which would result in the improvement of light-harvest ability and lower the HOMO energy levels of the target polymers. To further improve the performance of our polymer, we changed the BDT donor unit to a simple and small thiophene unit and synthesized the poly\{2,3-bis[(5-octylthio)thiophen-2-yl]quinoxaline-5,8-diyl-alt-thiophene-2,5-diyl\}(PTQTS) (Scheme 1), which could decrease the steric hindrance and increase the inter-chain $\pi-\pi$ stacking of polymer backbones. The UV-vis absorptions, energy levels, morphology and photovoltaic performances of the abovementioned three copolymers were evaluated to understand the relationships between their structures and properties. Using the conventional device structure, the polymer PTQTS displayed a promising PCE of $3.73 \%$ with $V_{\mathrm{oc}}$ of $0.76 \mathrm{~V}, J_{\mathrm{sc}}$ of $9.41 \mathrm{~mA} \mathrm{~cm}^{-2}$, FF of $52.3 \%$ under the illumination of AM $1.5 \mathrm{G} 100 \mathrm{~mW} \mathrm{~cm}{ }^{-2}$ without post-treatment, which was the best performance among the three copolymers because of its good planar and high hole mobility. The results indicated that the polymer PTQTS with thiophene as the donor unit and
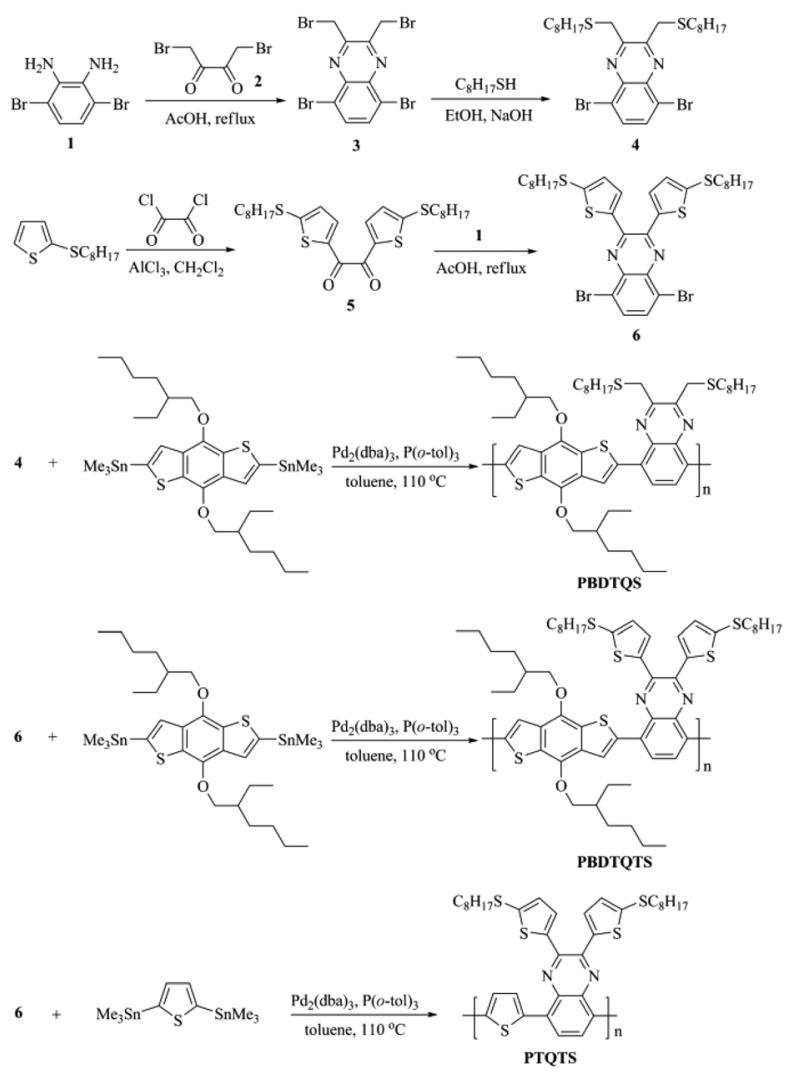

Scheme 1 Synthetic route for the monomers and polymers. 
QTS as the acceptor unit in the main chain, was a promising donor candidate in the application of polymer solar cells.

\section{Results and discussion}

\section{Synthesis and structural characterization}

The synthetic route of the monomers and copolymers is outlined in Scheme 1. 3,6-Dibromo-1,2-diamine $(\mathbf{1})^{42}$ condensed with 1,2-dibromobutane-2,3-dione (2) ${ }^{43}$ to yield 2,3-bis(bromomethyl)-5,8-dibromoquinoxaline (3). Compound 3 reacted with $N$-octylmercaptan in a stirred solution of $\mathrm{NaOH}$ and ethanol to produce 2,3-bis(n-octylthiomethyl)-5,8-dibromoquinoxaline (4). 2-(octylthio)-thiophene ${ }^{44}$ was dissolved in a solution of $\mathrm{CH}_{2} \mathrm{Cl}_{2}$ containing $\mathrm{AlCl}_{3}$ and oxalyl chloride to give 1,2-bis[(5octylthio)-thiophen-2-yl]ethane-1,2-dione (5). Then, 2,3-bis[(5octylthio)thiophen-2-yl]-5,8-dibromoquinoxaline (6) was prepared by closed loop reaction between compound (1) and compound (5) using acetic acid as the solvent and heating at $60{ }^{\circ} \mathrm{C}$ for $12 \mathrm{~h}$ under nitrogen atmosphere. PBDTQS, PBDTQTS and PTQTS were prepared by Stille cross-coupling reaction with yield of about $78-85 \%$. Further purification was carried out by Soxhlet extraction with methanol, hexane and chloroform, and the product was precipitated from methanol-chloroform system. Molecular weights and molecular weight distributions of these three polymers were measured by gel permeation chromatography (GPC) using tetrahydrofuran (THF) as eluent with narrowly distributed polystyrenes as the calibration standards. PBDTQS showed a number average molecular weight $\left(M_{\mathrm{n}}\right)$ of $23.1 \mathrm{kDa}$ and a polydispersity index (PDI) of 1.91. PBDTQTS showed $M_{\mathrm{n}}$ of $19.9 \mathrm{kDa}$, and PDI of 2.16. PTQTS showed $M_{\mathrm{n}}$ of $24.3 \mathrm{kDa}$, and PDI of 2.10. All the polymers were fully soluble in common organic solvents such as THF, chloroform, chlorobenzene (CB) and $o$-dichlorobenzene (ODCB).

\section{Thermal properties}

The thermal properties of PBDTQS, PBDTQTS and PTQTS were analyzed by thermo-gravimetric analysis (TGA). The degradation temperature $\left(T_{\mathrm{d}}\right)$ (with $5 \%$ weight lost) was found to be at 304, 370 and $320^{\circ} \mathrm{C}$ for PBDTQS, PBDTQTS and PTQTS, respectively (as shown in Fig. 1). Obviously, the thermal stabi-

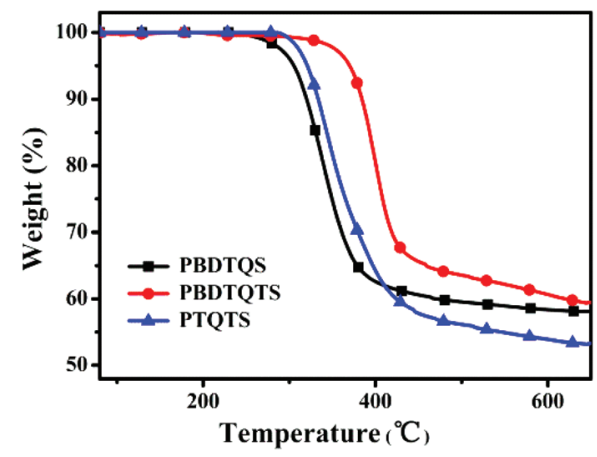

Fig. 1 TGA curves of the copolymers with a heating rate of $10^{\circ} \mathrm{C} \mathrm{min}-1$ under $\mathrm{N}_{2}$ atmosphere. lity of these quinoxaline-based polymers is adequate for their applications in PSCs and other optoelectronic devices.

\section{Optical properties}

The UV-vis absorption properties of the obtained copolymers were measured in both chloroform solution (Fig. 2a) and as thin films on quartz slides (Fig. 2b). As shown in Fig. 2, all the resulting copolymers had similar absorption profiles and showed two absorption peaks at around 380 and $600 \mathrm{~nm}$, which is a typical feature for D-A copolymers. The absorption peak around $380-410 \mathrm{~nm}$ originated from the $\pi-\pi^{*}$ transition of the polymer main chain, and the absorption in the wavelength range of 500-800 $\mathrm{nm}$ were mainly due to the charge transfer from the donor units to acceptor units. In comparison with PBDTQS, the maximum absorption peaks of PBDTQTS and PTQTS in the long wavelength range were obviously redshifted, suggesting that thiophene unit could increase the conjugated length in the backbone of the copolymers. A Similar behavior was observed for the absorption spectra of these copolymers as thin solid films (Fig. 2b). Compared to the absorption peaks in solution, the absorption peaks of the films in the wavelength range of 500-800 nm showed larger red-shifts around 25, 8, $51 \mathrm{~nm}$ for PBDTQS, PBDTQTS and PTQTS, respectively. The reason could be explained by the formation of $\pi$-stacked structures in the solid state which could facilitate charge transportation for photovoltaic applications. Moreover, it also indicated that PTQTS possessed stronger
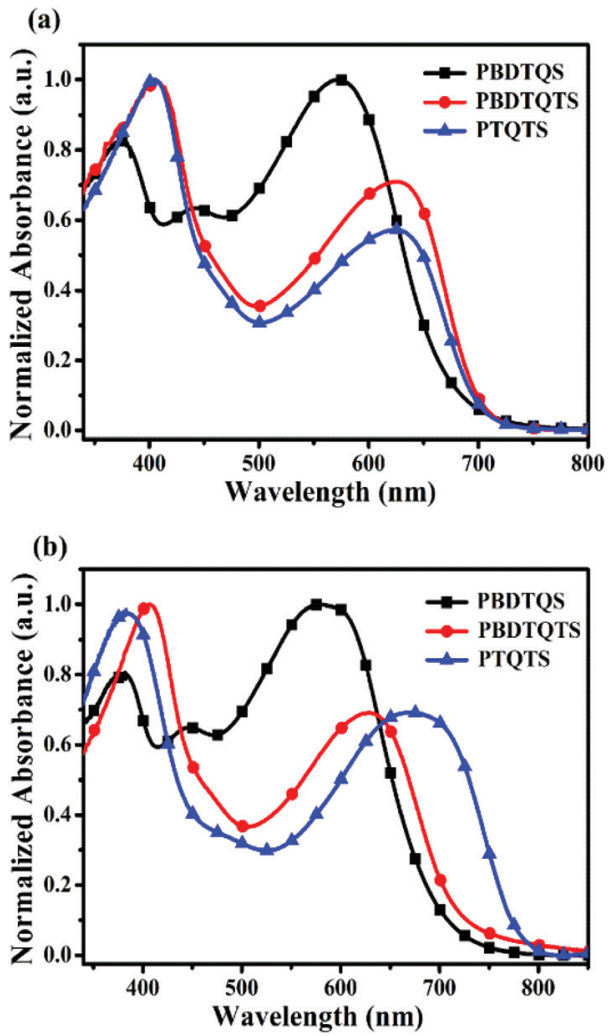

Fig. 2 UV-vis absorption spectra of copolymers (a) in $\mathrm{CHCl}_{3}$ solution and (b) as film. 
$\pi$-stacking ability than the other two copolymers in solid state due to the small thiophene unit, which could decrease the steric hindrance of building blocks and improve the interchain $\pi-\pi$ stacking. The optical band gaps calculated from the onset of the film absorption spectra were about 1.77, 1.70 and $1.58 \mathrm{eV}$ for PBDTQS, PBDTQTS and PTQTS, respectively. It is worth noting that the $E_{\mathrm{g}}^{\text {opt }}$ of PTQTS was considerably lower than those of PBDTQS and PBDTQTS, which would facilitate a high absorption in green-red region of the solar spectrum. Thus, PSCs based on PTQTS and $\mathrm{PC}_{61} \mathrm{BM}$ probably exhibited a better $J_{\mathrm{sc}}$ value and photovoltaic performance than that of other two polymers.

\section{Electrochemical properties}

To investigate the differences in electrochemical properties, the redox potentials of PBDTQS, PBDTQTS and PTQTS films deposited onto a platinum electrode were studied by cyclic voltammetry (CV) measurement. The HOMO and LUMO levels of polymers were calculated from their onset oxidation potential $\left(\varphi_{\text {ox }}\right)$ and onset reduction potential $\left(\varphi_{\text {red }}\right)$ according to the following equations: $E_{\mathrm{HOMO}}=-\mathrm{e}\left(\varphi_{\mathrm{ox}}+4.8-\varphi_{1 / 2}, \mathrm{FeCp}_{2}\right)(\mathrm{eV})$ and $E_{\text {LUMO }}=-\mathrm{e}\left(\varphi_{\text {red }}+4.8-\varphi_{1 / 2}, \mathrm{FeCp}_{2}\right)(\mathrm{eV})$, where the unit of potential is V (vs. SCE). ${ }^{45}$ As shown in Fig. 3, the onset oxidation potentials of PBDTQS, PBDTQTS and PTQTS were determined to be $0.88,0.88$ and $0.85 \mathrm{~V}$, corresponding to the HOMO energy levels of $-5.29,-5.29$ and $-5.26 \mathrm{eV}$, respectively. Compared with polymer TTQ $(-5.06 \mathrm{eV}),{ }^{28}$ these three copolymers showed lower HOMO levels due to the introduction of the alkylthio side chain. The onset reduction potentials of PBDTQS, PBDTQTS, and PTQTS were about $-0.78,-0.71$ and $-0.68 \mathrm{~V}$ and LUMO energy levels of the corresponding copoly-

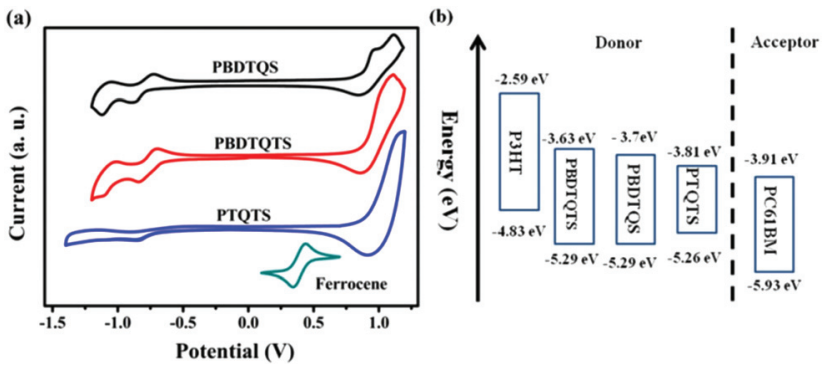

Fig. 3 (a) Cyclic voltammograms of the copolymer thin films on $\mathrm{Pt}$ electrodes in $0.1 \mathrm{M} \mathrm{Bu}_{4} \mathrm{NPF}_{6}-\mathrm{CH}_{3} \mathrm{CN}$ at a scan rate of $50 \mathrm{mV} \mathrm{s}^{-1}$, (b) energy level diagrams of the compounds in $\mathrm{BHJ}$ device. mers were estimated to be $-3.63,-3.70$ and $-3.72 \mathrm{eV}$, respectively. From the onset potentials of the oxidation and reduction processes, the band gaps $\left(E_{\mathrm{g}}\right)$ of PBDTQS, PBDTQTS and PTQTS were calculated to be about 1.66, 1.59 and $1.44 \mathrm{eV}$. The values were different from those obtained by the abovedescribed optical method, which was mainly due to the energy barriers of the charge transfer at the electrodes during the $\mathrm{CV}$ measurement. ${ }^{46}$ The energy levels of the materials used in the OPVs are shown in Fig. 3. The HOMO levels of these three copolymers were lower than that of $\mathrm{P} 3 \mathrm{HT},{ }^{47}$ as shown in Fig. 3. This implies that these three materials in PSCs might have possessed a higher $V_{\text {oc }}$ than the P3HT-based counterparts. The LUMO levels of these three copolymers were higher than that of $\mathrm{PC}_{61} \mathrm{BM}$; this induced electron-effective transfer at the donor-acceptor interface. The electrochemical data of the copolymers are summarized in Table 1.

\section{Photovoltaic properties}

Current density versus voltage $(J-V)$ curves of the PSCs based on PBDTQS, PBDTQTS and PTQTS were shown in Fig. 4. The PSCs devices were fabricated with a typical configuration of ITO/PEDOT $:$ PSS/polymers : $\mathrm{PC}_{61} \mathrm{BM} / \mathrm{Ca} / \mathrm{Al}$ (PEDOT $:$ PSS = poly(3,4-ethylenedioxythiophene) : poly(styrenesulfonate)). The copolymer film blended with the acceptor $\mathrm{PC}_{61} \mathrm{BM}$, which was spincoated from a CB solution, was used as the active layer of the photovoltaic device. The weight ratios of PBDTQS, PBDTQTS and PTQTS to $\mathrm{PC}_{61} \mathrm{BM}$ varied from $1: 1$ to $1: 3$ for device optimization; the $V_{\mathrm{oc}}, J_{\mathrm{sc}}, \mathrm{FF}, \mathrm{PCE}$ values of these devices under the illumination of AM $1.5 \mathrm{G} 100 \mathrm{~mW} \mathrm{~cm}^{-2}$ are collected in Table 2. A blend ratio of 1:2 was found to give the best results for all polymers. The three polymers exhibited the similar $V_{\mathrm{oc}}$ from 0.81 to $0.76 \mathrm{~V}$, which were higher than those of the reported quinoxaline derivatives without alkylthio substitute groups. ${ }^{27,28}$ PBDTQS showed PCE of $1.37 \%$ with high $V_{\mathrm{oc}}$ of $0.81 \mathrm{~V}, J_{\mathrm{sc}}$ of $3.35 \mathrm{~mA} \mathrm{~cm}{ }^{-2}$, and $\mathrm{FF}$ of $50.72 \%$. Although the highest $V_{\mathrm{oc}}$ $(0.81 \mathrm{~V})$ was obtained in the resulting copolymers, the device based on PBDTQS exhibited the lowest PCE of 1.37\%. PBDTQTS obtained PCE of $2.78 \%$ with high $V_{\text {oc }}$ of $0.80 \mathrm{~V}, J_{\mathrm{sc}}$ of $6.96 \mathrm{~mA}$ $\mathrm{cm}^{-2}$, and $\mathrm{FF}$ of $50.28 \%$. Compared with PBDTQS, PBDTQTS showed slightly better photovoltaic performance and a PCE of $2.78 \%$ was obtained due to the extended $\pi$-conjugated system and the improved planarity of backbone. In addition, the introduction of a thiophene ring could also improve the absorption capability of polymer films. Therefore, the $J_{\mathrm{sc}}$ of the device based on PBDTQTS was increased from 3.61 to $6.96 \mathrm{~mA} \mathrm{~cm} \mathrm{~cm}^{-2}$,

Table 1 Optical and electrochemical properties of the polymers

\begin{tabular}{|c|c|c|c|c|c|c|c|c|}
\hline Polymer & \multicolumn{2}{|c|}{ Solution } & \multicolumn{3}{|c|}{ Film } & $\mathrm{HOMO}^{b}(\mathrm{eV})$ & $\operatorname{LUMO}^{b}(\mathrm{eV})$ & $E_{\mathrm{g}}{ }^{c}(\mathrm{eV})$ \\
\hline PBDTQTS & 404 & 628 & 408 & 630 & 1.70 & -5.29 & -3.7 & 1.59 \\
\hline PTQTS & 404 & 628 & 382 & 674 & 1.58 & -5.26 & -3.72 & 1.44 \\
\hline
\end{tabular}

${ }^{a}$ Band gap estimated from the optical absorption band edge of the film. ${ }^{b}$ HOMO and LUMO levels were estimated from the onset of the oxidation and reduction peaks of cyclic voltammogram. ${ }^{c}$ Electrochemical band gap calculated from the difference of HOMO and LUMO. 


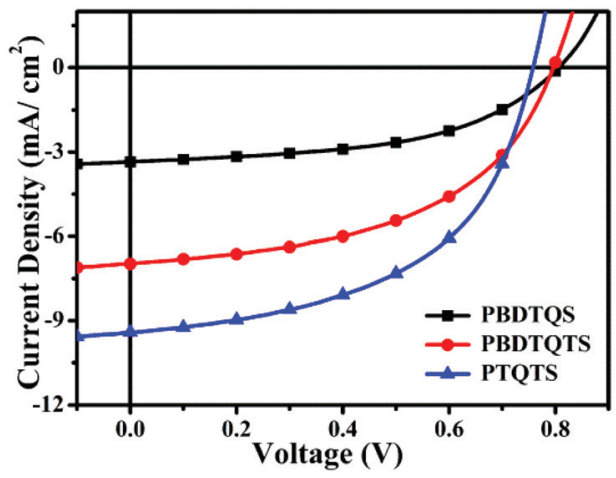

Fig. $4 J-V$ curves of the photovoltaic devices under the illumination of AM $1.5 \mathrm{G}, 100 \mathrm{~mW} \mathrm{~cm}^{-2}$.

Table 2 Characteristics of polymer solar cells based on PBDTQS, PBDTQTS, and PTQTS

\begin{tabular}{lcllll}
\hline Polymer : $\mathrm{PC}_{61} \mathrm{BM}$ & $\mathrm{w} / \mathrm{w}$ & $V_{\mathrm{oc}}(\mathrm{V})$ & $J_{\mathrm{sc}}\left(\mathrm{mA} \mathrm{cm}^{-2}\right)$ & $\mathrm{FF}$ & $\mathrm{PCE}(\%)$ \\
\hline PBDTQS & $1: 1$ & 0.80 & 2.44 & 44.43 & 0.86 \\
& $1: 2$ & 0.81 & 3.35 & 50.72 & 1.37 \\
PBDTQTS & $1: 3$ & 0.81 & 3.25 & 50.35 & 1.32 \\
& $1: 1$ & 0.82 & 4.57 & 38.12 & 1.43 \\
PTQTS & $1: 2$ & 0.80 & 6.96 & 50.28 & 2.78 \\
& $1: 3$ & 0.75 & 5.39 & 55.95 & 2.26 \\
& $1: 1$ & 0.77 & 9.43 & 48.80 & 3.54 \\
& $1: 2$ & 0.76 & 9.41 & 52.33 & 3.73 \\
& $1: 3$ & 0.75 & 7.20 & 59.52 & 3.22
\end{tabular}

which led to an improved PCE (from $1.37 \%$ to $2.78 \%$ ). Compared to PBDTQS and PBDTQTS, PTQTS gave the best PCE of $3.73 \%$ with $V_{\text {oc }}$ of $0.76 \mathrm{~V}, J_{\text {sc }}$ of $9.41 \mathrm{~mA} \mathrm{~cm}^{-2}$ and $\mathrm{FF}$ of $52.3 \%$. This was mainly due to the increased light absorption in long wavelength range of this polymer. It could be seen that replacing the BDT unit in PBDTQS and PBDTQTS with a smaller thiophene unit could reduce the steric hindrance of the backbone of PTQTS, which leads to an enhanced intermolecular $\pi-\pi$ stacking. Thus, the $J_{\mathrm{sc}}$ and FF of PTQTS were obviously improved compared with PBDTQS and PBDTQTS. The device performance of our polymer PTQTS, especially the $V_{o c}$ value, was lower than that of the reported polymer TQ1 by Ergang Wang's group, ${ }^{28}$ which was mainly due to the higher HOMO level of polymer PTQTS because the thiophene substitute group on quinoxaline unit may have stronger electron-donating nature than the phenyl group in TQ1. ${ }^{48}$

To verify the accuracy of the $J-V$ measurements, the corresponding external quantum efficiencies (EQE) of the devices were measured and shown in Fig. 5. All the three polymers displayed broadened absorption from $350-800 \mathrm{~nm}$. The optimum device PTQTS/PC ${ }_{61} \mathrm{BM}$ very efficiently harvests solar light with the maximum $\mathrm{EQE}$ of $61.8 \%$ at $420 \mathrm{~nm}$, and exhibits a much better photo-response in the range from 350 to $550 \mathrm{~nm}$. Moreover, the calculated $J_{\mathrm{sc}}$, by integrating the spectral response of the cells, were $3.28,6.91$, and 9.25 for PBDTQS: $\mathrm{PC}_{61} \mathrm{BM}$, PBDTQTS : $\mathrm{PC}_{61} \mathrm{BM}$ and $\mathrm{PTQTS}: \mathrm{PC}_{61} \mathrm{BM}$, respectively. The

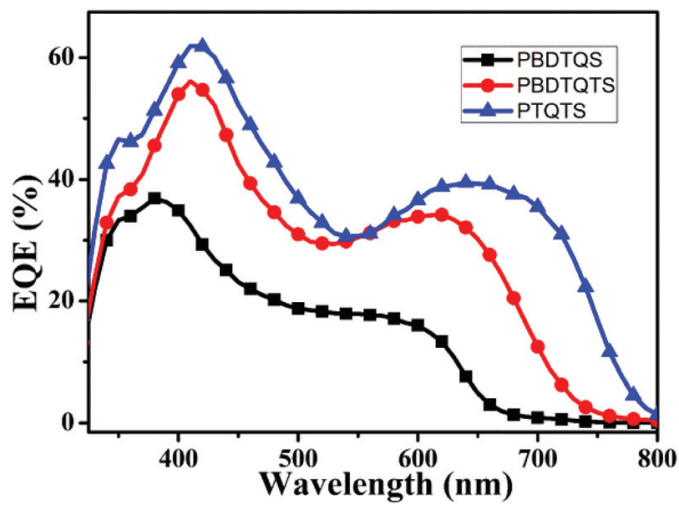

Fig. 5 EQE curves of the photovoltaic cells with polymers: $\mathrm{PC}_{61} \mathrm{BM}$ system illuminated by monochromatic light.

EQE spectra of the polymers : $\mathrm{PC}_{61} \mathrm{BM}(\mathrm{w}: \mathrm{w}, 1: 2)$ based device agreed well with the absorption spectra of the blends, and the highest EQE supported its highest $J_{\mathrm{sc}}$ value.

\section{Morphology}

In order to understand the effect of active layer morphology on the device performance of PBDTQS, PBDTQTS and PTQTS, tapping mode height images $(5 \mu \mathrm{m} \times 5 \mu \mathrm{m})$ and phase images $(5 \mu \mathrm{m} \times 5 \mu \mathrm{m})$ of copolymers : $\mathrm{PC}_{61} \mathrm{BM}$ blend films were investigated by atomic force microscopy (AFM). As shown in Fig. 6, the surface of PBDTQS : $\mathrm{PC}_{61} \mathrm{BM}$ blend film exhibited a root-meansquare roughness (RMS) of $2.09 \mathrm{~nm}$ and a large phase separation, which was not favorable for the charge transfer from the polymer to $\mathrm{PC}_{61} \mathrm{BM}$, thus limited the efficiency of the resulting device. ${ }^{47}$ The surfaces of PBDTQTS: $\mathrm{PC}_{61} \mathrm{BM}$ and PTQTS: $\mathrm{PC}_{61} \mathrm{BM}$ blend films spin-coated from $\mathrm{CB}$ showed relatively smooth surfaces with RMS of 1.51 and $1.80 \mathrm{~nm}$, respectively. Consequently, the rougher surface of the PBDTQS $\mathrm{PC}_{61} \mathrm{BM}$ blend film may affect the contact situation between the active layer and other layer of the PBDTQS based device, which may further influence the performance of the device. ${ }^{49,50}$
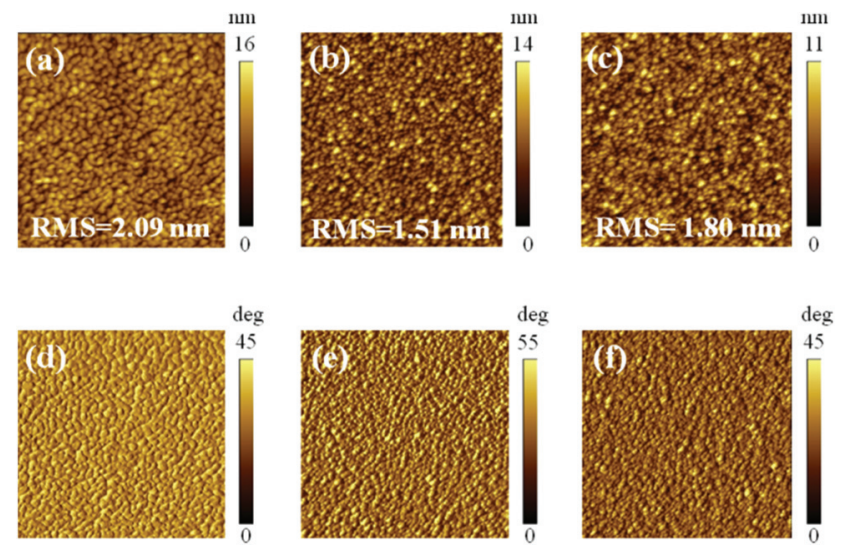

Fig. 6 AFM tapping mode height images of polymers: $\mathrm{PC}_{61} \mathrm{BM}$ films (upper row) (a) PBDTQS, (b) PBDTQTS, (c) PTQTS; and phase images of polymers: $\mathrm{PC}_{61} \mathrm{BM}$ films (lower row) (d) PBDTQS, (e) PBDTQTS, (f) PTQTS. The imaging size is $5 \mu \mathrm{m} \times 5 \mu \mathrm{m}$ in each panel. 


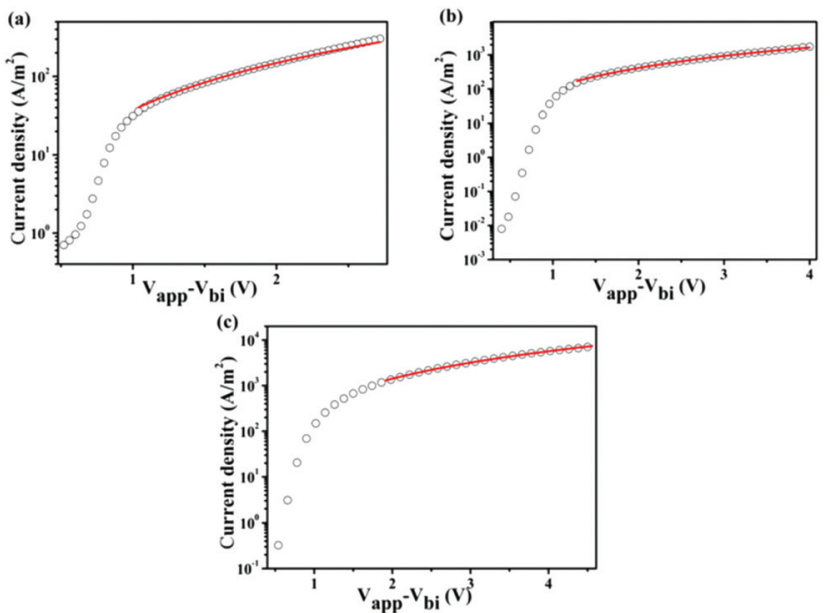

Fig. 7 Current voltage characteristics of the SCLC devices of these three copolymer blends: PBDTQS, PBDTQTS and PTQTS, respectively.

\section{Hole mobility}

In addition to the absorption and energy levels, charge carrier mobility is another crucial factor for achieving high-efficiency devices. The hole mobilities of the three polymers were measured using the space-charge-limited current (SCLC) method, with the device structure of ITO/PEDOT:PSS/ polymers : PC61BM/Au (as shown in Fig. 7). The SCLC is described as

$$
J_{\mathrm{SCLC}}=\frac{9}{8} \varepsilon_{0} \varepsilon_{\mathrm{r}} \mu_{\mathrm{h}} \frac{V^{2}}{L^{3}}
$$

here $J$ stands for current density, $\varepsilon_{0}$ is the permittivity of free space, $\varepsilon_{\mathrm{r}}$ is the relative dielectric constant of the transport medium, $\mu_{\mathrm{h}}$ is the hole mobility, $V$ is the internal potential in the device and $L$ is the thickness of the active layer. The internal potential $V$ is obtained by subtracting the built-in voltage $\left(V_{\mathrm{bi}}\right)$ and the voltage drop $\left(V_{\mathrm{s}}\right)$, obtained from the series resistance of the substrate, from the applied voltage $\left(V_{\text {appl }}\right)$, according to $V=V_{\text {appl }}-V_{\mathrm{bi}}-V_{\mathrm{s}}$. As shown in Fig. 7, according to eqn (1), the hole mobilities are calculated to be $1.66 \times 10^{-5}$ $\mathrm{cm}^{2} \mathrm{~V}^{-1} \mathrm{~s}^{-1}, 1.17 \times 10^{-4} \mathrm{~cm}^{2} \mathrm{~V}^{-1} \mathrm{~s}^{-1}$ and $2.05 \times 10^{-4} \mathrm{~cm}^{2} \mathrm{~V}^{-1}$ $\mathrm{s}^{-1}$ for PBDTQS, PBDTQTS and PTQTS, respectively. The higher hole mobility of PTQTS was enhanced mainly due to the improved inter-molecular interactions and ordered alignment of the blend film. The higher mobility would benefit for the exciton separation and transport. Therefore, the device based on PTQTS showed higher $J_{\text {sc }}$ and FF compared to the other two devices.

\section{Conclusions}

In summary, three copolymers (PBDTQS, PBDTQTS and PTQTS) with alkylthio side chain on the quinoxaline acceptor were designed and synthesized. The UV-vis absorptions, thermal stability, energy levels, morphology and photovoltaic characteristics of the three copolymers were systematically evaluated to understand the relationships between the polymer structures and the photovoltaic performances. Replacing the carbon atom in the side chain of polymer PBDTQS with a thiophene ring could increase the conjugation length in the side chain direction and improve the absorption in the visible region for the copolymers PBDTQTS and PTQTS. Furthermore, polymer PTQTS exhibited a more planar backbone and increased intermolecular $\pi$-stacking compared to PBDTQTS, which was due to the thiophene unit in PTQTS having a smaller size and less steric hindrance than those of BDT unit in PBDTQTS. The optimized polymer solar cell based on PTQTS showed a PCE of $3.73 \%$ with a $V_{\text {oc }}$ of $0.76 \mathrm{~V}$, a $J_{\text {sc }}$ of $9.41 \mathrm{~mA} \mathrm{~cm}^{-2}$ and a $\mathrm{FF}$ of $52.33 \%$ under AM $1.5 \mathrm{G} 100 \mathrm{~mW}$ $\mathrm{cm}^{-2}$, which is the best performance among these three copolymers. The results indicated that the polymer PTQTS with thiophene as the donor unit and QTS as the acceptor unit in the main chain, would be a promising donor candidate in the application of polymer solar cells.

\section{Experimental section}

\section{Materials}

All reagents and starting materials were purchased from Energy Chemical, J\&K, AlfaAesar and used without further purification, unless otherwise noted. 3,6-Dibromobenzene-1,2diamine (compound 1 in Scheme 1), ${ }^{38}$ 1,4-dibromobutane-2,3dione (compound 2 in Scheme 1), ${ }^{39}$-(octylthio)thiophene (compound 5 in Scheme 1$)^{40}$ were synthesized according to the methods reported in the literature. All air and water sensitive reactions were performed under argon atmosphere. Toluene, tetrahydrofuran (THF), ether were dried over $\mathrm{Na}$ /benzophenone and freshly distilled prior to use.

\section{Characterization}

${ }^{1} \mathrm{H}$ NMR and ${ }^{13} \mathrm{C}$ NMR spectra were recorded on a Bruker DRX-600 spectrometer. APCI-TOF HRMS were performed on Bruker Maxis UHR-TOF (both positive and negative ion reflector mode). The ultraviolet-visible (UV-vis) spectra were measured on a Varian Cary 50 spectrophotometer. Cyclic voltammetry (CV) was performed on a CHI660D electrochemical workstation with a solution of tetrabutylammonium hexafluorophosphate $\left(\mathrm{Bu}_{4} \mathrm{NPF}_{6}\right)(0.1 \mathrm{M})$ in acetonitrile. A three-electrode cell consisting of a glassy carbon working electrode, a Pt counter electrode and a saturated calomel reference electrode (SCE) was used with a $100 \mathrm{mV} \mathrm{s}^{-1}$ scan rate. The potential of ferrocene/ferrocenium ( $\left.\mathrm{Fc} / \mathrm{Fc}^{+}\right)$was measured to be $0.4 \mathrm{~V}$ compared to the SCE electrode under the same conditions. It is assumed that the redox potential of $\mathrm{Fc} / \mathrm{Fc}^{+}$has an absolute energy level of $-4.8 \mathrm{eV}$ to vacuum. AFM images were acquired with an Agilent 5400 scanning probe microscope with a nanodrive controller in tapping mode. Thermal gravimetric analysis (TGA) was performed by an ATA409 at a heating rate of $10{ }^{\circ} \mathrm{C}$ $\min ^{-1}$, under the protection of $\mathrm{N}_{2}$ atmosphere. The molecular weights of polymers were measured by the GPC method, and polystyrene was used as the standard and THF as eluent. 


\section{Fabrication and characterization of polymer solar cells}

PSC devices with the typical structure of ITO/PEDOT:PSS/ polymers: $\mathrm{PC}_{61} \mathrm{BM} / \mathrm{Ca} / \mathrm{Al}$ were fabricated under the similar conditions as follows: all cells were fabricated on ITO coated glass substrates with a nominal sheet resistance of $15 \Omega$ per sq. The ITO-coated glass substrates were sequentially washed by ultrasonication in detergent, ultra-pure water, acetone, and isopropyl alcohol for $20 \mathrm{~min}$. The substrates were then oxygen plasma treated for $20 \mathrm{~min}$, spin-coated with a $30 \mathrm{~nm}$ layer of PEDOT: PSS at $4000 \mathrm{rpm}$, and dried in air for $20 \mathrm{~min}$ at $150{ }^{\circ} \mathrm{C}$. The polymers and $\mathrm{PC}_{61} \mathrm{BM}$ were dissolved in deoxygenated anhydrous chlorobenzene in the weight ratios of $1: 1$, $1: 2$, and $1: 3$, respectively, and stirred overnight in a glovebox filled with $\mathrm{N}_{2}$. Typical concentration of the polymers/ $\mathrm{PC}_{61} \mathrm{BM}$ blending solution was $24 \mathrm{mg} \mathrm{ml} \mathrm{m}^{-1}$. An active layer consisting of the blend of polymer and $\mathrm{PC}_{61} \mathrm{BM}$ was then spin coated on PEDOT: PSS with a thickness of about $80 \mathrm{~nm}$. Subsequently, $\mathrm{Ca}(10 \mathrm{~nm})$ and $\mathrm{Al}(100 \mathrm{~nm})$ were thermally evaporated under a vacuum of $2 \times 10^{-4} \mathrm{~Pa}$ on the surface of active layer as a cathode. The cell's active area was $0.1 \mathrm{~cm}^{2}$. The current density-voltage $(J-V)$ characteristics were recorded with a Keithley 2420 source measurement unit under simulated AM $1.5 \mathrm{G}, 100 \mathrm{~mW} \mathrm{~cm}{ }^{-2}$ irradiation from a Newport solar simulator. Light intensity was calibrated with a standard silicon solar cell. The external quantum efficiencies (EQE) of solar cells were analyzed using a certified Newport incident photon conversion efficiency (IPCE) measurement system.

\section{Syntheses of the monomers and polymers}

2,3-Bis(bromomethyl)-5,8-dibromoquinoxaline

(3). Compound 1 (2.659 g, $10 \mathrm{mmol})$ and compound $2(2.439 \mathrm{~g}$, $10 \mathrm{mmol}$ ) were dissolved in acetic acid $(100 \mathrm{~mL})$ with vigorous stirring. The reaction mixture was refluxed overnight. After removal of acetic acid under reduced pressure, the residue was purified by column chromatography on silica gel (hexaneethyl acetate, $\mathrm{v} / \mathrm{v}, 50 / 1$ ) to produce a light yellow solid 3 (3.073 g, 65\%). ${ }^{1} \mathrm{H} \mathrm{NMR}\left(\mathrm{CDCl}_{3}, 600 \mathrm{MHz}\right) \delta$ (ppm): 7.99 (s, 2H), $5.04(\mathrm{~s}, 4 \mathrm{H})$.

\section{2,3-Bis(n-octylthiomethyl)-5,8-dibromoquinoxaline}

$N$-Octylmercaptan $(1.931 \mathrm{~g}, 13.2 \mathrm{mmol})$ was added to a stirred solution of $\mathrm{NaOH}(0.528 \mathrm{~g}, 13.2 \mathrm{mmol})$ in ethanol $(40 \mathrm{~mL})$ followed by the addition of 2, 3-bis(bromomethyl)-5, 8-dibromoquinoxaline $(2.843 \mathrm{~g}, 6 \mathrm{mmol})$ dissolved in THF at room temperature. After stirring for $16 \mathrm{~h}$, the solvent was removed under reduced pressure, and then purified by column chromatography on silica gel (hexane). A light-yellow solid could be obtained by recrystallization in ethanol. Yield: $\sim 70 \% .{ }^{1} \mathrm{H}$ NMR $\left(\mathrm{CDCl}_{3}, 600 \mathrm{MHz}\right) \delta(\mathrm{ppm}): 7.87(\mathrm{~s}, 2 \mathrm{H}), 4.20(\mathrm{~s}, 4 \mathrm{H}), 2.49(\mathrm{t}$, $4 \mathrm{H}), 1.61-1.18(\mathrm{~m}, 24 \mathrm{H}), 0.87(\mathrm{t}, 6 \mathrm{H}) ;{ }^{13} \mathrm{C} \mathrm{NMR}\left(\mathrm{CDCl}_{3}\right.$, $150 \mathrm{MHz}) \delta$ (ppm): 154.40, 139.06, 132.80, 123.34, 34.24, 31.80, 31.37, 29.20, 29.19, 29.17, 28.80, 22.65, 14.11.

MS (MALDI-TOF): calcd for $\mathrm{C}_{26} \mathrm{H}_{40} \mathrm{~N}_{2} \mathrm{Br}_{2} \mathrm{~S}_{2}\left[\mathrm{M}^{+}\right]$, 604.10; found 604.11 .

1,2-Bis $[(5-o c t y l t h i o)-t h i o p h e n-2-y l]$ ethane-1,2-dione (5). A suspension of $\mathrm{AlCl}_{3}(1.6 \mathrm{~g}, 12 \mathrm{mmol})$ in $\mathrm{CH}_{2} \mathrm{Cl}_{2}(15 \mathrm{~mL})$ was added dropwise into a solution of 2-(octylthio)-thiophene $(2.741 \mathrm{~g}, 12 \mathrm{mmol})$ and oxalyl chloride $(0.42 \mathrm{~mL}, 5 \mathrm{mmol})$ in $\mathrm{CH}_{2} \mathrm{Cl}_{2}$. The red mixture was stirred at room temperature for $4 \mathrm{~h}$. The reaction was then quenched with ice and concentrated $\mathrm{HCl}(1 \mathrm{~mL})$. After intensive stirring for $1 \mathrm{~h}$ the dark green organic phase was separated, washed by $2 \mathrm{M} \mathrm{HCl}$ and $\mathrm{NaHCO}_{3}$ (aq.) solutions, respectively, and dried over $\mathrm{MgSO}_{4}$. After the evaporation of the solvent a blue-green solid remained, which was suspended in ethanol. Subsequent filtration and washing with ethanol and diethyl ether provided a green solid. A green color solid was obtained in $78 \%$ yield. ${ }^{1} \mathrm{H}$ NMR $\left(\mathrm{CDCl}_{3}, 600 \mathrm{MHz}\right) \delta$ (ppm): 7.97 (d, 2H), 7.01 (d, 2H), $3.08(\mathrm{t}, 4 \mathrm{H}), 1.82-1.30(\mathrm{~m}, 24 \mathrm{H}), 0.91(\mathrm{t}, 6 \mathrm{H})$.

2,3-Bis[(5-octylthio)thiophen-2-yl]-5,8-dibromoquinoxaline (6). Compound 1 (2.659 g, $10 \mathrm{mmol})$ and compound 5 $(5.108 \mathrm{~g}, 10 \mathrm{mmol})$ were dissolved in acetic acid $(100 \mathrm{~mL})$ with vigorous stirring. The reaction mixture was refluxed overnight. After the removal of acetic acid under reduced pressure, the residue was purified by column chromatography on silica gel (hexane) to obtain a light orange solid $6(4.814 \mathrm{~g}, 65 \%) .{ }^{1} \mathrm{H}$ NMR $\left(\mathrm{CDCl}_{3}, 600 \mathrm{MHz}\right) \delta(\mathrm{ppm}): 7.84(\mathrm{~s}, 2 \mathrm{H}), 7.45(\mathrm{~d}, 2 \mathrm{H})$, $6.69(\mathrm{~d}, 2 \mathrm{H}), 2.98(\mathrm{t}, 4 \mathrm{H}), 1.77-1.29(\mathrm{~m}, 24 \mathrm{H}), 0.91(\mathrm{t}, 6 \mathrm{H}) ;{ }^{13} \mathrm{C}$ NMR $\left(\mathrm{CDCl}_{3}, 150 \mathrm{MHz}\right) \delta(\mathrm{ppm}): 146.19,142.79,142.03$, 138.62 , 133.06, 131.16, 130.56, 122.97, 38.18, 31.81, 29.42, 29.19, 29.12, 28.57, 22.66, 14.12.

MS (MALDI-TOF): calcd for $\mathrm{C}_{32} \mathrm{H}_{40} \mathrm{~N}_{2} \mathrm{Br}_{2} \mathrm{~S}_{2}\left[\mathrm{M}^{+}\right]$, 740.04; found 740.05 .

Poly\{4,8-bis(2-ethylhexyloxy)-benzo[1,2-b:4,5- $\left.b^{\prime}\right]$-dithiophenealt-2,3-bis(n-octylthiomethyl) quinoxaline\} (PBDTQS). In a $50 \mathrm{~mL}$ flask, compound 4 (151.2 mg, $0.25 \mathrm{mmol}), 2,6$-bis(trimethyltin)-4,8-bis(2-ethylhexyl)benzo[1,2- $\left.b: 4,5-b^{\prime}\right]$ dithiophene (193.05 $\mathrm{mg}, 0.25 \mathrm{mmol}$ ), tris(dibenzylideneacetone)dipalladium $\left[\mathrm{Pd}_{2}(\mathrm{dba})_{3}, 2.29 \mathrm{mg}\right]$ and tris(o-tolyl)phosphine $\left[\mathrm{P}(\mathrm{o}-\mathrm{Tol})_{3}, 4.57 \mathrm{mg}\right]$ were dissolved in $8 \mathrm{~mL}$ of toluene and stirred at $60{ }^{\circ} \mathrm{C}$ under a nitrogen atmosphere for $3 \mathrm{~h}$. Subsequently, the reactants were stirred for $24 \mathrm{~h}$ at $100{ }^{\circ} \mathrm{C}$ under nitrogen atmosphere. After cooling, the solution was poured into methanol. The polymer was collected by filtration and sequentially soxhlet-extracted with methanol, hexane, and chloroform. The chloroform solution was concentrated into a small volume and then again poured into methanol. The precipitate was collected by filtration and dried in vacuum at $50{ }^{\circ} \mathrm{C}$ overnight, which afforded PBDTQS (200 mg) as a green-black solid with a yield of $78 \%$. ${ }^{1} \mathrm{H} \mathrm{NMR}\left(\mathrm{CDCl}_{3}\right.$, $600 \mathrm{MHz}) \delta$ (ppm): 8.02 (br, 6H), 4.35 (br, 8H), 2.57 (br, 4H), 1.57 (br, 60H).

Gel permeation chromatography (tetrahydrofuran, polystyrene standard, $25^{\circ} \mathrm{C}$ ): number-average molecular weight $=$ $23.1 \mathrm{kDa}$, polydispersity index $=1.91$.

Poly\{4,8-bis(2-ethylhexyloxy)-benzo[1,2-b:4,5-b']-dithiophenealt-2,3-bis[(5-octylthio)thiophen-2-yl]quinoxaline\}(PBDTQTS). Compound 7 (185.18 mg, $0.25 \mathrm{mmol}$ ), 2,6-bis(trimethyltin)4,8-bis(2-ethylhexyl)benzo[1,2- $\left.b: 4,5-b^{\prime}\right]$ dithiophene (193.08 mg, $0.25 \mathrm{mmol}), \mathrm{Pd}_{2}(\mathrm{dba})_{3}(2.29 \mathrm{mg})$ and $\mathrm{P}(o-\mathrm{Tol})_{3}(4.57 \mathrm{mg})$ were stirred for $24 \mathrm{~h}$ in $8 \mathrm{~mL}$ toluene at $100{ }^{\circ} \mathrm{C}$ under nitrogen atmosphere. Yield: $211 \mathrm{mg}, 80 \%$ as deep green solid. ${ }^{1} \mathrm{H}$ NMR 
$\left(\mathrm{CDCl}_{3}, 600 \mathrm{MHz}\right) \delta(\mathrm{ppm}): 7.26(\mathrm{br}, 6 \mathrm{H}), 7.45(\mathrm{br}, 4 \mathrm{H}), 6.69(\mathrm{~d}$, $4 \mathrm{H}), 2.98$ (br, 60H). $M_{\mathrm{n}}=19.9 \mathrm{kDa}, \mathrm{PDI}=2.16$.

Poly\{2,3-bis[(5-octylthio)thiophen-2-yl]quinoxaline-5,8-diylalt-thiophene-2,5-diyl\}(PTQTS). Compound 7 (185.18 $\mathrm{mg}$, $0.25 \mathrm{mmol}$ ), 2,5-bis(trimethylstannyl)thiophene (102.44 mg, $0.25 \mathrm{mmol}), \mathrm{Pd}_{2}(\mathrm{dba})_{3}(2.29 \mathrm{mg})$ and $\mathrm{P}(o-\mathrm{Tol})_{3}(4.57 \mathrm{mg})$, stirred for $24 \mathrm{~h}$ in $8 \mathrm{~mL}$ toluene at $100{ }^{\circ} \mathrm{C}$ under nitrogen atmosphere. Yield: $147 \mathrm{mg}, 85 \%$ as blue-green solid. ${ }^{1} \mathrm{H}$ NMR $\left(\mathrm{CDCl}_{3}, 600 \mathrm{MHz}\right) \delta(\mathrm{ppm}): 7.24$ (br, 6H), 2.98 (br, 4H), 1.19 (br, $30 \mathrm{H}) \cdot M_{\mathrm{n}}=24.3 \mathrm{kDa}, \mathrm{PDI}=2.10$.

\section{Acknowledgements}

This work was supported by National Natural Science Foundation of China (21204097, 51173199 and 61107090), Ministry of Science and Technology of China (2014CB643501, 2010DFA52310), Shandong Provincial Natural Science Foundation (ZR2011BZ007), Qingdao Municipal Science and Technology Program (14-2-4-28-jch and 11-2-4-22-hz).

\section{Notes and references}

1 J. Chen and Y. Cao, Acc. Chem. Res., 2009, 42, 1709-1718.

2 G. Yu, J. Gao, J. Hummelen, F. Wudl and A. Heeger, Science, 1995, 270, 1789-1790.

3 G. Y. Chen, S. C. Lan, P. Y. Lin, C. W. Chu and K. H. Wei, J. Polym. Sci., Part A: Polym. Chem., 2010, 48, 4456-4464.

4 H. Wu, B. Qu, Z. Cong, H. Liu, D. Tian, B. Gao, Z. An, C. Gao, L. Xiao, Z. Chen, H. Liu, Q. Gong and W. Wei, React. Funct. Polym., 2012, 72, 897-903.

5 X. X. Sun, W. C. Chen, Z. K. Du, X. C. Bao, G. N. Song, K. Q. Guo, N. Wang and R. Q. Yang, Polym. Chem., 2013, 4, 1317-1322.

6 Y. Li, Acc. Chem. Res., 2012, 45, 723-733.

7 B. S. Rolczynski, J. M. Szarko, H. J. Son, Y. Liang, L. Yu and L. X. Chen, J. Am. Chem. Soc., 2012, 134, 4142-4152.

8 Q. Liu, X. Bao, S. Wen, Z. Du, L. Han, D. Zhu, Y. Chen, M. Sun and R. Yang, Polym. Chem., 2014, 5, 2076-2082.

9 C. J. Brabec, N. S. Sariciftci and J. C. Hummelen, Adv. Funct. Mater., 2001, 11, 15-26.

10 X. Guo, C. Cui, M. Zhang, L. Huo, Y. Huang, J. Hou and Y. Li, Energy Environ. Sci., 2012, 5, 7943.

11 C. C. Cui, W. Y. Wong and Y. F. Li, Energy Environ. Sci., 2014, 7, 2276-2284.

12 C. Piliego, T. W. Holcombe, J. D. Douglas, C. H. Woo, P. M. Beaujuge and J. M. Frechet, J. Am. Chem. Soc., 2010, 132, 7595-7597.

13 H. Zhou, L. Yang, A. C. Stuart, S. C. Price, S. Liu and W. You, Angew. Chem., Int. Ed., 2011, 50, 2995-2998.

14 L.-M. Chen, Z. Hong, G. Li and Y. Yang, Adv. Mater., 2009, 21, 1434-1449.

15 Z. He, C. Zhang, X. Xu, L. Zhang, L. Huang, J. Chen, H. Wu and Y. Cao, Adv. Mater., 2011, 23, 3086-3089.
16 H. J. Son, B. Carsten, I. H. Jung and L. Yu, Energy Environ. Sci., 2012, 5, 8158-8170.

17 Y. P. Zou, A. Najari, P. Berrouard, S. Beaupre, B. R. Aich, Y. Tao and M. Leclerc, J. Am. Chem. Soc., 2010, 132, 53305331.

18 A. Gadisa, W. Mammo, L. M. Andersson, S. Admassie, F. Zhang, M. R. Andersson and O. Inganäs, Adv. Funct. Mater., 2007, 17, 3836-3842.

19 J. You, L. Dou, K. Yoshimura, T. Kato, K. Ohya, T. Moriarty, K. Emery, C. C. Chen, J. Gao, G. Li and Y. Yang, Nat. Commun., 2013, 4, 1446.

20 C. C. Chen, W. H. Chang, K. Yoshimura, K. Ohya, J. You, J. Gao, Z. Hong and Y. Yang, Adv. Mater., 2014, 26, 56705677.

21 J. Hou, Z. Tan, Y. Yan, Y. He, C. Yang and Y. Li, J. Am. Chem. Soc., 2006, 128, 4911-4916.

22 Y. Li and Y. Zou, Adv. Mater., 2008, 20, 2952-2958.

23 L. Han, X. Bao, T. Hu, Z. Du, W. Chen, D. Zhu, Q. Liu, M. Sun and R. Yang, Macromol. Rapid Commun., 2014, 35, 1153-1157.

24 Z. Du, Y. Chen, W. Chen, S. Qiao, S. Wen, Q. Liu, D. Zhu, M. Sun and R. Yang, Chem. - Asian J., 2014, 9, 26212627.

25 Y. Chen, Z. Du, W. Chen, Q. Liu, L. Sun, M. Sun and R. Yang, Org. Electron., 2014, 15, 405-413.

26 L. Huo, S. Zhang, X. Guo, F. Xu, Y. Li and J. Hou, Angew. Chem., Int. Ed., 2011, 50, 9697-9702.

27 R. Duan, L. Ye, X. Guo, Y. Huang, P. Wang, S. Zhang, J. Zhang, L. Huo and J. Hou, Macromolecules, 2012, 45, 3032-3038.

28 E. Wang, L. Hou, Z. Wang, S. Hellstrom, F. Zhang, O. Inganas and M. R. Andersson, Adv. Mater., 2010, 22, 5240-5244.

29 B. Gao, C. Gao, H. Wu, W. Que and W. Wei, Mater. Lett., 2014, 122, 74-77.

30 R. Kroon, A. Lundin, C. Lindqvist, P. Henriksson, T. T. Steckler and M. R. Andersson, Polymer, 2013, 54, 1285-1288.

31 J. Mei and Z. Bao, Chem. Mater., 2014, 26, 604-615.

32 T. Lei, J.-Y. Wang and J. Pei, Chem. Mater., 2014, 26, 594603.

33 R. M. Mairo Souto, K. Hinkelmann, H. Eckert and F. Wudl, Macromolecules, 1990, 23, 1268-1279.

34 G. Chen, H. Sasabe, Y. Sasaki, H. Katagiri, X.-F. Wang, T. Sano, Z. Hong, Y. Yang and J. Kido, Chem. Mater., 2014, 26, 1356-1364.

35 S. Zhang, L. Ye, W. Zhao, D. Liu, H. Yao and J. Hou, Macromolecules, 2014, 47, 4653-4659.

36 W. Y. Zhou, F. Jin, X. B. Huang, X. M. Duan and X. W. Zhan, Macromolecules, 2012, 45, 7823-7828.

37 J. A. Schneider, A. Dadvand, W. Wen and D. F. Perepichka, Macromolecules, 2013, 46, 9231-9239.

38 C. Pozo-Gonzalo, T. Khan, J. J. W. McDouall, P. J. Skabara, D. M. Roberts, M. E. Light, S. J. Coles, M. B. Hursthouse, H. Neugebauer, A. Cravino and N. S. Sariciftci, J. Mater. Chem., 2002, 12, 500-510. 
39 L. Huo, Y. Zhou and Y. Li, Macromol. Rapid Commun., 2009, 30, 925-931.

40 D. Lee, S. W. Stone and J. P. Ferraris, Chem. Commun., 2011, 47, 10987-10989.

41 D. Lee, E. Hubijar, G. J. D. Kalaw and J. P. Ferraris, Chem. Mater., 2012, 24, 2534-2540.

42 R. Yang, R. Tian, J. Yan, Y. Zhang, J. Yang, Q. Hou, W. Yang, C. Zhang and Y. Cao, Macromolecules, 2005, 38, 244-253.

43 G. Buchi, E. Demole and A. F. Thomas, J. Org. Chem., 1973, 38, 123-125.

44 Y. Huang, L. Huo, S. Zhang, X. Guo, C. C. Han, Y. Li and J. Hou, Chem. Commun., 2011, 47, 8904-8906.
45 J. L. Bredas, R. Silbey, D. S. Boudreaux and R. R. Chance, J. Am. Chem. Soc., 1983, 105, 6555-6559.

46 S. C. Price, A. C. Stuart, L. Yang, H. Zhou and W. You, J. Am. Chem. Soc., 2011, 133, 4625-4631.

47 B. C. Thompson and J. M. Frechet, Angew. Chem., Int. Ed., 2008, 47, 58-77.

48 B. Sun, W. Hong, Z. Yan, H. Aziz and Y. Li, Adv. Mater., 2014, 2636-2642.

49 Y. Zhang, J. Zou, H.-L. Yip, K.-S. Chen, J. A. Davies, Y. Sun and A. K. Y. Jen, Macromolecules, 2011, 44, 47524758.

50 N. Wang, L. Sun, X. Zhang, X. Bao, W. Zheng and R. Yang, RSC Adv., 2014, 4, 25886-25891. 